\title{
The relationship between oxidative stress and acute ischemic stroke severity and functional outcome
}

\author{
Wael M. Elsayed ${ }^{1}$, El-Hady A. Abdel-Gawad ${ }^{1}$, Dalia I. A. Mesallam² ${ }^{2^{*}}$ and Tamer S. El-Serafy ${ }^{1}$
}

\begin{abstract}
Background: Cerebral ischemia initiates an oxidative stress response in the brain which is a composite process that involves many oxidative stress biomarkers. High levels of malondialdehyde (MDA) in patients with acute ischemic stroke had been found. The evaluation of oxidative stress in the acute stage may contribute to improve the post ischemic stroke outcome.

Objective: The aim of the current study to assess MDA level, as an oxidative stress biomarker, in acute ischemic stroke on admission and its relation with stroke severity on admission and also, its relation with three months shortterm outcome.

Methods: Forty-two patients (20 males and 22 females) with acute ischemic stroke were prospectively enrolled in follow-up cohort study. Serum MDA was measured within $24 \mathrm{~h}$ after admission. We studied the relationship between MDA and stroke severity and functional outcome after 3 months assessed by National Institute of Health Stroke Scale (NIHSS) and modified Rankin Scale (mRS) respectively.

Results: Serum MDA levels correlated significantly with clinical short-term stroke outcome after 3 months $(p<0.001)$.

Conclusion(s): These data provide evidence that the MDA (an oxidative stress biomarker) may be used as predictor for functional outcome in acute ischemic stroke.
\end{abstract}

Keywords: Ischemic stroke, MDA, NIHSS, mRS

\section{Introduction}

Oxidative stress is defined as a disturbance in the prooxidant/antioxidant balance that favors oxidation. This disturbance arises due to extra free radicals' manufacture over the cellular capacity to produce an active antioxidant response. This will result in macromolecular injury such as cellular proteins, lipids, or DNA hindering their normal function and is concerned to countless diseases such as, diabetes, cancer, neurodegeneration, atherosclerosis, and aging [1].

\footnotetext{
* Correspondence: diamaae@yahoo.com

${ }^{2}$ Forensic Medicine and Clinical Toxicology Department, Faculty of Medicine, Zagazig University, Zagazig, El-Sharkia, Egypt

Full list of author information is available at the end of the article
}

Investigational and clinical studies propose that oxidative stress plays a central role in brain damage which follows a stroke [2-4]. Oxidative stress has a reflective effect in stroke pathogenesis due to the high vulnerability of the brain to reactive oxygen species (ROS)-induced damage. The brain is a target for various reasons, including high peroxidizable lipids concentrations, low defensive antioxidants levels, high oxygen consumption, and high iron levels that act as pro-oxidants through stress [5].

Malondialdehyde (MDA) is the final lipid peroxidation (LPO) product. This compound is a reactive aldehyde and is one of the several reactive electrophile species that cause cellular toxicity. The aldehyde production is used as biomarker to measure the oxidative stress level [6].

\section{Springer Open}

(c) The Author(s). 2020 Open Access This article is licensed under a Creative Commons Attribution 4.0 International License, which permits use, sharing, adaptation, distribution and reproduction in any medium or format, as long as you give appropriate credit to the original author(s) and the source, provide a link to the Creative Commons licence, and indicate if changes were made. The images or other third party material in this article are included in the article's Creative Commons licence, unless indicated otherwise in a credit line to the material. If material is not included in the article's Creative Commons licence and your intended use is not permitted by statutory regulation or exceeds the permitted use, you will need to obtain permission directly from the copyright holder. To view a copy of this licence, visit http://creativecommons.org/licenses/by/4.0/. 
Moreover, high circulating levels of MDA in patients with ischemic stroke have been found and there were been found an association between circulating high levels of MDA and neurological functional outcome in ischemic stroke patients [7-10].

The present study was conducted to estimate the relationship between the oxidative stress biomarker MDA and acute ischemic stroke severity, and 3 months short term motor functional outcome.

\section{Patients and methods}

This prospective cohort study was done during period between May 2018 and March 2019, we prospectively analyzed 42 consecutive patients ( 20 males and 22 females) with first-ever ischemic stroke admitted within a week of the stroke symptoms onset to the Neurology Critical Care and Stroke Units, Neurology Department, Zagazig University Hospitals. Patients were identified according to Bogousslavsky et al. [11] and established by brain computed tomography (CT) and/or magnetic resonance imaging (MRI).

Our exclusion criteria were history of recurrent stroke, hemorrhagic stroke. Patients who were lost during follow-up for any cause other than death were also omitted from the study.

\section{Methods}

An informed consent was obtained from all participants or their first-degree relatives and they were told about the aim of the study, and were informed that the data would be used for scientific purposes only.

All patients, in this prospectively cohort study, were subjected to the following:

\section{[A] On admission}

1. Clinical assessment: including detailed history taking paying special attention to past medical history obtained from the patients or their relatives.

2. Full examination (general and neurological) including evaluation of stroke severity on admission using: The National Institute of Health Stroke Scale (NIHSS) was performed for initial evaluation of stroke severity, within the first $24 \mathrm{~h}$ on admission [12], in this study, a score of $(0)$ is measured for no stroke symptoms, (1-4) is measured for minor, (5-15) is measured for moderate, (16-20) is measured for moderate to severe, and (21-42) measured for severe.

3. Laboratory investigations including complete blood count, blood glucose level, liver and kidney functions, and lipid profile.
4. Neuro-imaging study: The patients in the study had CT scan and/or MRI of the brain to prove the diagnosis of stroke.

5. Oxidative stress biomarker: serum MDA were done for all stroke patients after admission within $24 \mathrm{~h}$ at the Central Research Lab, Medical Biochemistry and Molecular Biology Department, Faculty of Medicine, Zagazig University.

Serum malondialdehyde (MDA) level (nmol/L), as oxidative stress marker, measured according to Ohkawa et al. [13]:

Principle: The principle of the method is based on that MDA can react with thiobarbituric acid in acidic media at temperature of $95^{\circ} \mathrm{C}$ for $30 \mathrm{~min}$ to form thiobarbituric acid reactive product. The resultant pink product can be measured spectrophotometrically at $534 \mathrm{~nm}$.

Calculation:

$$
\begin{aligned}
& \text { Malondialdehyde in serum } \\
& \quad=(\text { A Sample } \div \text { A Standard }) \times 10 \mathrm{nmol} / \mathrm{L} \text {. }
\end{aligned}
$$

[B] Follow-up assessment of the patients: Modified rankin scale (mRS) was performed after 3 months post stroke to assess short-term outcome and disability of stroke. Modified rankin scale scores the disability of patients into points from 0-6 according to the degree of disability. Patients with score $<2$ were considered had favorable outcome, while patients with score 2-5 were considered had unfavorable outcome and dead patients had score 6 [14], in this study a score of (6) is measured for dead, (2-5) is measured for unfavorable outcome and $(<2)$ is measured for favorable outcome.

\section{Statistical analysis}

The data were tabulated and statistically analyzed using the Statistical Package for Social Science (SPSS) Program version 14.0.0 software package. The qualitative data were presented in the form of numbers and percentage. The $T$ test and one-way ANOVA were used as tests of significance. Pearson's correlation coefficient rank test, it was used to rank different variables against each other in linear correlation which may be positive or negative. Probability ( $p$ value of $>0.05$ indicates non-significant results; $p$ value $\langle 0.05$ means significant difference, $p>$ 0.001 for highly significant result.

\section{Results}

This cohort study was conducted on 42 first ever acute ischemic stroke patients, (20 males, 22 females), their 
ages ranged from 53 to 72 with a mean age $(62.95 \pm$ 4.21(SD)), who were admitted in Neurology Critical Care Unit and Stroke Units of Zagazig University Hospitals within 7 days of symptoms onset.

The serum level of MDA was done at admission, $42.9 \%$ of the studied ischemic stroke patients had MDA level more than $2.65 \mathrm{nmol} / \mathrm{L}$ compared to $57.1 \%$ had MDA level less than $2.65 \mathrm{nmol} / \mathrm{L}$, and the results of clinical assessment scales which were done for stroke patient at admission (NIHSS), 66.7\% had moderate to severe score compared to $33.3 \%$ had moderate score, and after 3 months (mRS), dead was $11.9 \%, 50 \%$ had unfavorable outcome compared to $38.1 \%$ had favorable outcome, are presented in Table 1.

There was no statistically significant $(p>0.05)$ difference between patients with moderate and moderate to severe scores of NIHSS regarding mean values of MDA as shown in Table 2.

Furthermore, there was statistically significant increase in mean value of MDA in patients with unfavorable outcome $(p<0.001)$ compared to patients with favorable outcome. However, there was no statistically significant $(p>$ 0.05 ) increase in mean value of MDA in dead patients compared to favorable and also, there was no statistically significant $(p>0.05)$ increase in mean value of MDA in dead patients compared to unfavorable outcome patients as shown in Table 3. Also, there was statistically highly significant $(p<0.001)$ positive correlation between mRS, and MDA as shown in Table 4 and Fig. 1.

\section{Discussion}

Stroke characterizes an imperative public health problem. It is the third most prevalent reason of death after heart disease and cancer, also it considered as a foremost source of long-term disability [15].

Table 1 Serum malondialdehyde, clinical severity and functional outcome of the studied ischemic stroke patients

\begin{tabular}{llll}
\hline & & \multicolumn{2}{l}{ Patients numbers } \\
\cline { 3 - 4 } & & Numbers & $\%$ \\
\hline MDA & MDA $>\mathbf{2 . 6 5}$ & 18 & $42.9 \%$ \\
& MDA $<\mathbf{2 . 6 5}$ & 24 & $57.1 \%$ \\
NIHSS & No stroke symptoms (0) & 0 & $0.0 \%$ \\
& Minor (1-4) & 0 & $0.0 \%$ \\
& Moderate (5-15) & 14 & $33.3 \%$ \\
& Moderate to severe (16-20) & 28 & $66.7 \%$ \\
& Severe (21-42) & 0 & $0.0 \%$ \\
& Dead $=\mathbf{6}$ & 5 & $11.9 \%$ \\
& Unfavorable outcome (2-5) & 21 & $50 \%$ \\
& Favorable outcome (< 2) & 16 & $38.1 \%$ \\
\hline
\end{tabular}

MDA malondialdehyde, NIHSS National Institutes of Health Stroke, mRS modified Rankin Scale, $N$ number, $\%$ percentage
Table 2 Relation between NIHSS and malondialdehyde in ischemic stroke patients

\begin{tabular}{llll}
\hline NIHSS & MDA & $t$ & $\begin{array}{l}P \\
\text { value }\end{array}$ \\
\hline Moderate $(\boldsymbol{n}=\mathbf{1 4})$ & $3.69 \pm 2.42$ & 0.533 & $0.597 \#$ \\
Moderate to severe $(\boldsymbol{n}=\mathbf{2 8})$ & $3.31 \pm 2.09$ & & \\
\hline
\end{tabular}

MDA malondialdehyde, NIHSS National Institutes of Health Stroke, $M \pm S D$ mean \pm standard deviation

"Non-significant $(p>0.05)$

Stroke survivors remain to be at advanced risk of disability and death, and it is of great clinical importance to expect outcome in acute stroke. Plentiful clinical variables (e.g., advanced age and symptom severity) have been recognized as probable predictors of outcome. Furthermore, countless biomarkers have been proposed to predict ischemic stroke outcome [16, 17].

Malondialdehyde (MDA) is an end-product of the radical-initiated oxidative breakdown of poly-unsaturated fatty acids and, hence, it is a commonly measured biomarker of oxidative stress [18].

The study was prospective cohort study included 42 patients (20 males and 22 females) their ages ranged from 53 to 72 years with a mean age $(62.95 \pm 4.21$ (SD) with the first ever acute ischemic stroke within 7 days of symptoms onset. The patients were sequentially recruited from Neurology Critical Care Unit and Neurology Stroke Unit, Neurology Department, Zagazig University Hospitals.

The results of our study were $66.7 \%$ of patients had moderate to severe NIHSS score (16-20) compared to $33.3 \%$ of patients had moderate NIHSS score (5-15). This is in agreement with the results of Mendioroz et al. [19] who stated that $59.9 \%$ of patients (on admission) showed NIHSS score (16-20). Also, Mansour et al. [20] recorded in a cohort study that their patients NIHSS median value at $24 \mathrm{~h}$ was $22(16-30)$ and at $72 \mathrm{~h}$ was 20 (11-30), otherwise Soliman et al. [21] reported that $61.7 \%$ of their patients show NIHSS moderate score (5$15)$, and moderate to severe in 11.4.

Table 3 Relation between mRS and Malondialdehyde in ischemic stroke patients

\begin{tabular}{|c|c|c|c|}
\hline $\mathrm{mRS}$ & $\begin{array}{l}\mathrm{MDA} \\
(M \pm \mathrm{SD})\end{array}$ & $F$ & $\begin{array}{l}p \\
\text { value }\end{array}$ \\
\hline Favorable outcome $(n=16)$ & $2.23 \pm 1.58$ & \multirow[t]{3}{*}{5.484} & \multirow[t]{3}{*}{$0.008^{* *}$} \\
\hline Unfavorable outcome $(n=21)$ & \multirow[t]{2}{*}{$4.4 \pm 2.12^{a}$} & & \\
\hline Dead $(n=5)$ & & & \\
\hline \multicolumn{4}{|c|}{$\begin{array}{l}\text { MDA malondialdehyde, } m R S \text { modified Rankin Scale, } M \pm S D \text { mean } \pm \\
\text { standard deviation } \\
* * \text { Highly significant }(p<0.001) \\
\text { a } p<0.001 \\
{ }^{b} p>0.05 \text { compared to favorable outcome } \\
{ }^{c} p>0.05 \text { compared to unfavorable outcome }\end{array}$} \\
\hline
\end{tabular}


Table 4 Correlation between mRS and malondialdehyde

\begin{tabular}{lll}
\hline Variable & MDA & \\
\cline { 2 - 3 } & $r$ & $p$ value \\
\hline mRS & 0.54 & $0.001^{* *}$
\end{tabular}

MDA malondialdehyde, $m R S$ modified Rankin Scale, $r$ coefficient of Spearman's correlation

**Significant $(p<0.05)$

In our study, $42.9 \%$ of the studied ischemic stroke patients had MDA level more than $2.65 \mathrm{nmol} / \mathrm{L}$, while $57.1 \%$ of patients had MDA level less than $2.65 \mathrm{nmol} / \mathrm{L}$. Similar percentages of elevation of MDA level in acute ischemic stroke patients $(21-52 \%)$ were recorded by Yaseen et al. [22], Lorente et al. [23], and Silina et al. [24].

In this study, the unfavorable functional outcome (mRS $2-5$ ) found in $50 \%$ of cases, $38.1 \%$ had favorable outcome $(\mathrm{mRS}<2)$, and $11.9 \%$ of patients were dead $(\mathrm{mRS}=6)$.

The outcome of our patients as regards the disability is quietly similar to the previous studies like that of Mendioroz et al. [19] who found that $55.3 \%$ of patients displayed a worse prognosis (mRS 2-5) at 3 months follow-up. In addition, Mansour et al. [20] reported mortality (19.7\%) and unfavorable outcome (mRS 2-5) at 3 months follow-up (56.7\%) and Soliman et al. [21] found that $56.3 \%$ of their patients showed unfavorable functional outcome mRS (2-5).

In the current study, concerning relationship between MDA and National Institutes of Health Stroke Scale (NIHSS), we found no significant relation between level of MDA and stroke severity when assessed by NIHSS score on admission. Our result goes in hand with Shoeibi et al. [25] who reported that there was a non- significant relation between NIHSS and MDA $(p=$ 0.791). Also, Ferhat et al. [26] who reported that there were no significant relations between the NIHSS value and oxidative stress biomarkers. Nevertheless, this was in disagreement with Yaseen et al. [22] who stated that the MDA levels on the day of admission and after 7 days correlate positively with the stroke severity as measured by NIHSS score.

Demirkaya et al. [27] reported significant relations between MDA levels and stroke severity on NIHSS. They rational this significance as follow: there is huge generation of free radicals (MDA) through ischemia in the penumbral tissue which has a least oxygen supply. The degree of damage induced by free radical be contingent with the antioxidant defense mechanism. In severe stroke, the availability of antioxidants cannot cope up with the abrupt upsurge in free radicals due to greater tissue damage amount. The antioxidant enzymes are inducible enzymes hence their transcription and synthesis take time. Consequently, in the initial phase, there is an increase in lipid peroxidation due to failure of defense mechanisms that reflects the volume of tissue damage and henceforth the stroke severity.

We could not detect any significant relation between levels of MDA and NIHSS; however, these MDA levels were measured only at the initial presentation, and follow-up measurements could help to illuminate MDA changes and ischemic stroke severity.

As regarding the relationship between the stroke outcome (functional disability evaluated by mRS, there was highly statistically significant difference between patients with unfavorable and favorable outcomes of mRS and

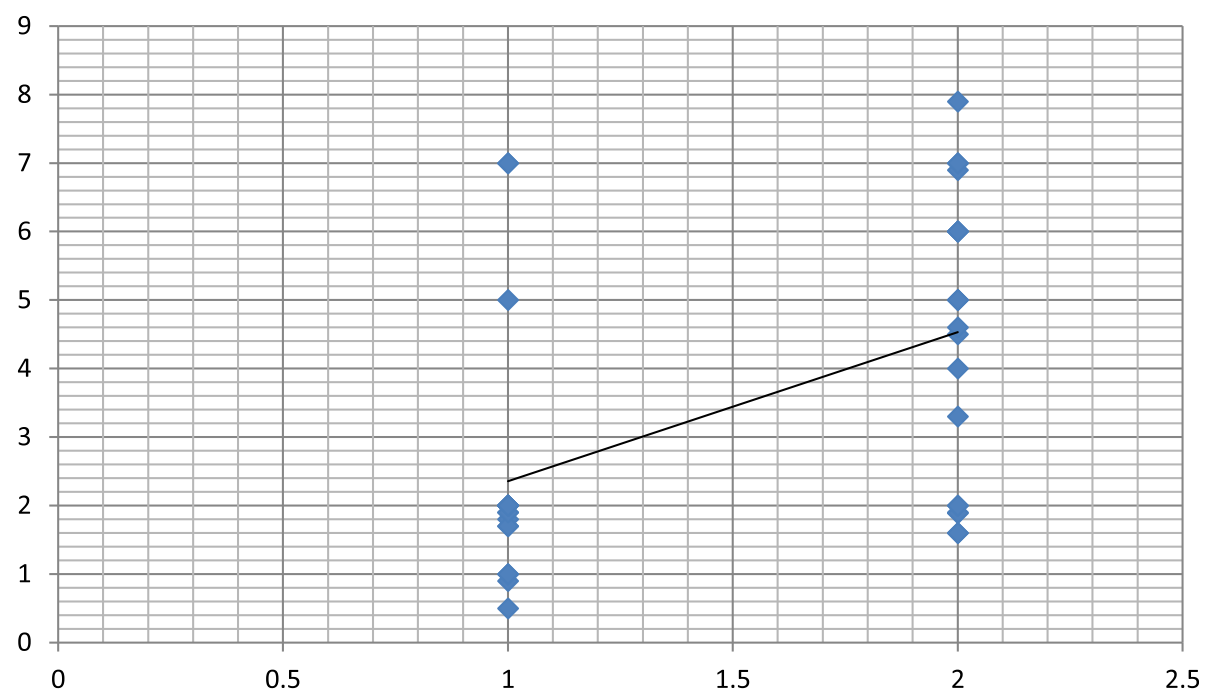

Correlation between MDA and mRS

Fig. 1 Correlation between MDA and mRS 
mean values of MDA, and we found statistically significant positive correlation between mRS and MDA level.

The existing study revealed a statistically high significant difference between stroke patients with 3 months favorable functional outcome $(\mathrm{mRS}<2)$ and those with unfavorable outcome (mRS 2-5) as regarding the mean values of MDA. Similarly, we found high significant positive correlation between mRS and MDA levels. Our results are quietly similar to a previous study of Tsai et al. [28] who reported a significant positive correlation between MDA levels and acute ischemic stroke outcome at 3 months based on mRS.

Also, Cherubini et al. [29] found a significant positive correlation between the MDA levels on admission in stroke patients' functional outcome by mRS after 1 week. In addition, Yaseen et al. [22] reported that MDA levels on admission and after 7 days prophesied the patients' functional disability on the 7th day and subsequently 6 months by mRS.

Lipid peroxidation (LPO) brought by asynuclein misfolding might play a vital role in the cellular mechanism of neuronal cell injury. In addition, LPO products could act as possible triggers of the p53 signaling pathway and cause membrane organization disturbance and loss of mitochondrial DNA functionally [23].

The restriction of this study, that serum MDA levels were only estimated for all patients within the first $24 \mathrm{~h}$ after admission. It may be indispensable to conduct a further longitudinal study determining serum MDA levels at multiple time points after stroke and appraising the prognostic value of MDA at later times.

The inconsistency of results is credited to a deficient sample size, study differences in population- and patient-level characteristics (i.e., socio-demographics and clinical factors), methodology).

Our findings should be considered preliminary, and additional clinical trials with MDA should be directed to explain whether modulation of oxidative stress in patients with stroke may support therapeutic indication in order to influence the ischemic stroke severity and outcome (functional). Hence, future studies will be compulsory to explore whether MDA imitates the severity and functional outcome after stroke in a greater sample and in groups with more consistency.

\section{Conclusion}

We concluded that high serum MDA levels on admission are autonomously predicted the unfavorable functional outcome of ischemic stroke at 3 months follow-up by modified Rankin Scale (mRS).

\section{Abbreviations}

ROS: Reactive oxygen species; NIHSS: National Institute of Health Stroke Scale; mRS: Modified Rankin Scale; MDA: Malondialdehyde; LPO: Lipid peroxidation

\section{Acknowledgements}

Not applicable.

\section{Authors' contributions}

WME, EAA, DIAM, and TSSE carried out this work. EAA and DIAM designed the study, DIAM had done the statistical analysis and wrote the manuscript. WME, EAA, and TSSE did the literature search, and coordinated the research team. WME, DIAM, and TSSE collected the patients, and gathered clinical data, and reviewed the manuscript. All authors were involved in drafting the article or revising it critically for important intellectual content, and all authors approved the final version to be published.

\section{Funding}

There is no source of funding for the research.

\section{Availability of data and materials}

The datasets used and/or analyzed during the current study are available from the corresponding author on reasonable request with the permission of the Faculty of Medicine, Zagazig University, Egypt.

\section{Ethics approval and consent to participate}

The study was approved from the Institutional Ethics Committee of Faculty of Medicine, Zagazig University (ZU-IRB\#: 4815/26-8-2018). A written consent was taken from all of the participants after explaining the details, benefits as well as risks to them. Consent for publication has been obtained from the participants involved in the study to report their individual patient data.

\section{Consent for publication}

Not applicable

\section{Competing interests}

The authors declare that they have no competing interests.

\section{Author details}

${ }^{1}$ Neurology Department, Faculty of Medicine, Zagazig University, El-Sharkia, Egypt. ${ }^{2}$ Forensic Medicine and Clinical Toxicology Department, Faculty of Medicine, Zagazig University, Zagazig, El-Sharkia, Egypt.

Received: 7 June 2020 Accepted: 29 June 2020

Published online: 16 July 2020

\section{References}

1. Ray PD, Huang BW, Tsuji Y. Reactive oxygen species homeostasis and redox regulation in cellular signaling. Cell signal. 2012;24:981-90.

2. Moskowitz MA, Lo EH, ladecola C. The science of stroke: mechanisms in search of treatments. Neuron. 2010;67:181-98.

3. Chen H, Yoshioka H, Kim GS, Jung EJ, Okami N, Sakata H, et al. Oxidative stress in ischemic brain damage: mechanisms of cell death and potential molecular targets for neuroprotection. Antioxid Redox Sign. 2011;14:150517.

4. Thanoon IA, Abdul-Jabbar HA, Taha DA. Oxidative stress and C-reactive protein in patients with cerebrovascular accident (ischaemic stroke): the role of ginkgo biloba extract. Sultan Qaboos Univ Med J. 2012;12:197-205.

5. Saeed SA, Shad KF, Saleem T, Javed F, Khan MU. Some new prospects in the understanding of the molecular basis of the pathogenesis of stroke. Exp Brain Res. 2007;182:1-10.

6. Oboh G, Akinyemi AJ, Ademiluyi AO. Antioxidant and inhibitory effect of red ginger (Zingiber Officinale Vai. Rubra) and white ginger (Zingiber Officinale Roscoe) on $\mathrm{Fe}^{2+}$ induced lipid peroxidation in rat brain in vitro. Exp. Toxicol. Pathol. 2012;64:31-6.

7. Polidori MC, Cherubini A, Stahl W, Senin U, Sies H, Mecocci P. Plasma carotenoid and malondialdehyde levels in ischemic stroke patients: relationship to early outcome. Free Radic Res. 2002;36:265-8.

8. Ozkul A, Akyol A, Yenisey C, Arpaci E, Kiylioglu N, Tataroglu C. Oxidative stress in acute ischemic stroke. J Clin Neurosci. 2007;14:1062-6.

9. Silina EV, Rumiantseva SA, Bolevich SB, Men'shova NI. Course of free radical processes and prognosis of ischemic and hemorrhagic stroke. Zh Nevrol Psikhiatr Im S S Korsakova. 2011;111:36-42.

10. Lorente L, Martín MM, Abreu-González P, Domínguez-Rodríguez A, Labarta $L$, Díaz C. Prognostic value of malondialdehyde serum levels in severe sepsis: a multicenter study. PLoS One. 2013;8:1-9. 
11. Bogousslavsky J, Diserens K, Rothacher G, Sturm J, Thrift AG. Stroke selected topics in seminars in clinical neurology, Munsat TL (ed), Demos Medical Publishing. New York. 2006;4:1-65.

12. Brott T, Marler JR, Olinger CP, Adams HP Jr, Tomsick T, Barsan WG, et al. Measurements of acute cerebral infarction: lesion size by computed tomography. Stroke. 1989;20:871-5.

13. Ohkawa H, Ohishi N, Yagi K. Assay for lipid peroxides in animal tissues by thiobarbituric acid reaction. Anal. Biochem. 1979;95:351-8.

14. Swieten V, Koudstaal PJ, Visser MC, Schouten HJA, Gijn JV. Nterobserver agreement for-the assessment of handicap in stroke patients. Stroke. 1988; 19:604-7.

15. Lloyd-Jones D, Adams RJ, Brown TM, Mercedes CA, Shifan DA, Giovanni DE, et al. Executive summary: heart disease and FU stroke statistics 2010 update: a report from the American Heart Association. Circulation. 2010;121:948-54.

16. Faiz K, Thommessen B, Gunnar E, Omland T, Rønning OM. Prognostic value of high-sensitivity cardiac troponin $\mathrm{T}$ in acute ischemic stroke. J Stroke Cerebrovasc Dis. 2014;23(2):241-9.

17. Gaillard F. "Ischaemic stroke". Radiopaedia.org. 2019; Retrieved 23 April 2019.

18. Giera M, Lingeman H, Niessen WM. Recent advancements in the LC-and GC-based analysis of malondialdehyde (MDA): a brief overview. Chromatographia. 2012;75(9-10):433-40.

19. Mendioroz M, Ferna'ndez-Cadenas A, Rosell P, Delgado S, DominguesMontanari M, Ribo' A, et al. Osteopontin predicts long-term functional outcome among ischemic stroke patients. J Neurol. 2011;258:486-93.

20. Mansour OY, Megahed MM, Abd Elghany EH. Acute ischemic stroke prognostication, comparison between Glasgow Coma Score, NIHS Scale and Full Outline of UnResponsiveness Score in intensive care unit. Alexandria Journal of Medicine. 2015;51:247-53.

21. Soliman RH, Oraby MI, Fathy M, Essam AM. Risk factors of acute ischemic stroke in patients presented to Beni-Suef University Hospital: prevalence and relation to stroke severity at presentation. The Egyptian Journal of Neurology. Psychiatry and Neurosurgery. 2018;54:1-9.

22. Yaseen Z, Chowdhury D, Shantaram M, Agarwal S, Sheela K. Prognostic significance of plasma homocysteine and malondialdehyde in patients with acute ischemic stroke. Intern J Pharma Research and Health Sciences. 2015; 3(3):727-36.

23. Lorente L, Martin MM, Perez-Cejas A, Abreu-Gonzalez P, Ramos L, Argueso $M$, et al. Association between total antioxidant capacity and mortality in ischemic stroke patients. Ann. Intensive Care. 2016;6, 39 1-6.

24. Silina EV, Orlova AS, Rumyantseva SA, Bolevich SB. Free-radical processes in stroke patients with vascular comorbidity. Biol Med (Aligarh). 2016;8(7):33440.

25. Shoeibi A, Razmi N, Ghabeli JA, Hashemy SI. The evaluation and comparison of oxidative stress in hemorrhagic and ischemic stroke. Caspian J Neurol Sci. 2017:3(11):206-13.

26. Ferhat I, Ozcan E, Zeynep SO, Tolga O, Akkan A, Salim S, et al. The relationship of oxidative stress parameters with infarct volume and National Institutes of Health Stroke Scale in ischemic stroke. Turkish Journal o Biochemistry - Türk Biyokimya Dergisi. 2015;40(4):275-81.

27. Demirkiya S, Topcuoglu MA, Aydin A, Ulas US, Isimer Al, Vural O Malondialdehyde, glutathione peroxidise and superoxide dismutase in peripheral blood erythrocytes of patients with acute cerebral ischemia. Eur J Neurol. 2001:8:43.

28. Tsai N-W, Chang Y-T, Huang C-R, Lin Y-J, Lin W-C, Chenget B-C et al. Association between oxidative stress and outcome in different subtypes of acute ischemic stroke. BioMed Research International, 2014, Article ID 256879, 7 pages. https://doi.org/10.1155/2014/256879.

29. Cherubini A, Polidori C, Brenocchi M. Antioxidant profile and early outcome in stroke patients. Stroke. 2000;31:2295-300.

\section{Publisher's Note}

Springer Nature remains neutral with regard to jurisdictional claims in published maps and institutional affiliations.

\section{Submit your manuscript to a SpringerOpen ${ }^{\circ}$ journal and benefit from:}

- Convenient online submission

- Rigorous peer review

- Open access: articles freely available online

- High visibility within the field

- Retaining the copyright to your article

Submit your next manuscript at $\boldsymbol{\nabla}$ springeropen.com 